\title{
Dynamic Pulse Buckling of Composite Stanchions in the Sub-Cargo Floor Area of a Civil Regional Aircraft
}

\author{
Andrea Sellitto ${ }^{1, *(\mathbb{D}}$, Francesco Di Caprio ${ }^{2}\left(\mathbb{D}\right.$, Michele Guida ${ }^{3}\left(\mathbb{D}\right.$, Salvatore Saputo ${ }^{1(\mathbb{C}}$ \\ and Aniello Riccio ${ }^{1}$ (D) \\ 1 Department of Engineering, University of Campania Luigi Vanvitelli, via Roma 29, 81031 Aversa, Italy; \\ salvatore.saputo@unicampania.it (S.S.); aniello.riccio@unicampania.it (A.R.) \\ 2 CIRA-Italian Aerospace Research Centre, via Maiorise snc, 81043 Capua, Italy; f.dicaprio@cira.it \\ 3 Department of Industrial Engineering, University of Naples Federico II, p.le Tecchio 80, 80125 Naples, Italy; \\ michele.guida@unina.it \\ * Correspondence: andrea.sellitto@unicampania.it
}

Received: 15 July 2020; Accepted: 11 August 2020; Published: 14 August 2020

check for updates

\begin{abstract}
This work is focused on the investigation of the structural behavior of a composite floor beam, located in the cargo zone of a civil aircraft, subjected to cyclical low-frequency compressive loads with different amplitudes. In the first stage, the numerical models able to correctly simulate the investigated phenomenon have been defined. Different analyses have been performed, aimed to an exhaustive evaluation of the structural behavior of the test article. In particular, implicit and explicit analyses have been considered to preliminary assess the capabilities of the numerical model. Then, explicit non-linear analyses under time-dependent loads have been considered, to predict the behavior of the composite structure under cyclic loading conditions. According to the present investigation, low-frequency cyclic loads with peak values lower than the static buckling load value are not capable of triggering significant instability.
\end{abstract}

Keywords: dynamic pulse buckling; composite stanchion; FE analysis; nonlinear analysis; crashworthiness

\section{Introduction}

Buckling is an instability phenomenon typical of "thin" structures (characterized by at least one very small dimension compared to the others). Usually, buckling has been considered a purely static phenomenon. The classic example is that of the Euler beam in which a beam stuck at one end is loaded from the tip to the other, with a compressive load lower than the limit of elasticity of the material. Theoretically, if the force is perfectly centered and the beam is free of imperfections, the latter would remain in equilibrium under the action of any load. In order for the instability to occur, it is mandatory to destabilize the beam by means of an external action, immediately removed. After the perturbation, three cases can occur, depending on the applied load: The beam returns to the initial equilibrium configuration (stable equilibrium); the beam moves to a new equilibrium condition different from the initial one (indifferent equilibrium); the beam moves away indefinitely from the initial equilibrium configuration (unstable equilibrium). The so-called buckling load is the lowest of the loads for which equilibrium is indifferent. However, buckling can also be caused by loads that vary over time [1-3]. The application of a time-dependent axial load to a beam, which then induces lateral vibrations and can eventually lead to instability, is something that has been investigated by many authors [4-10].

Generally, dynamic buckling depends on prescribed dynamic loads, and is distinguished between buckling from oscillatory loads and buckling from transient loads, so two forms of dynamic buckling are classified: Vibration and pulse buckling. 
Vibration buckling is characterized by oscillating loads producing amplification of the vibrations up to unacceptable values, and, in the absence of damping or nonlinear effects, a phenomenon similar to vibration resonance is predicted. In the vibration buckling, the force producing the instability is considered as a parameter multiplying the displacement, while in the vibration resonance, the load exciting the motion is evaluated as an applied force.

In pulse buckling, the presence of applied transient loads generates much larger and unacceptable amplitudes than the static buckling load of the bar as a result of the plastic response or large-deformation post-buckled state. The pulse buckling is characterized by buckling increasing rather than oscillating, and the modes produce wavelengths larger than the Euler wavelength for a given load.

The dynamic buckling of the column in an aircraft landing stanchion is a great deal and, in this work, the structural behavior of a composite floor beam subjected to low-frequency cyclic load conditions has been investigated. Indeed, the structural limits of beam-like structures is driven by their stability, rather than by their strength. The loss of stability induced by static loads is a well-known phenomenon, extensively investigated [11]. However, the loads that actually act on the structures are characterized by dynamic behavior, which can result in dynamic instability [12-15]. For these reasons, more detailed studies on the dynamic buckling phenomenon became mandatory in order to accurately predict the structural limits of the components subjected to realistic loads [16].

Dynamic buckling has a relatively recent history. One of the first research studies on dynamic buckling can be found in [17], where a theoretical solution considering a simply supported rectangular plate subjected to varying floor loads over time has been developed. In [18], a criterion that relates dynamic buckling to the duration of the load has been introduced. The effects of high-intensity and short-duration loads have been studied in [19]. According to the investigation, long-lasting critical dynamic buckling loads may be of less intensity than the corresponding static buckling loads.

In [20], a numerical and experimental investigation was performed on composite laminated shells by correlating their natural vibration frequencies and mode shapes with the buckling loads and modes. Moreover, parametric studies on the dynamic instability of carbon-fiber-reinforced plastic (CFRP) cylindrical shells were introduced in [21]. Different parameters were considered, such as the shape and the duration of pulse loading, and the initial geometric imperfection of the structure. According to the study, the dynamic load factor (DLF), defined as the ratio between the dynamic and the static buckling loads, is higher than that if short-pulse-duration loadings are used. Then, as the pulse duration increases, the DLF decreases, being lower than that in the vicinity of the natural frequency of the structure.

Other works have focused on the investigation of dynamic buckling on damaged composite structures. In [22], the nonlinear dynamic pulse buckling of a plate with embedded delamination was numerically investigated, and the DLF was computed. Different types of pulse loadings (sinusoidal, exponential, and rectangular) and different delamination sizes and depths were considered. Moreover, in [23], the dynamic instability of damaged composite components was studied, and the effects of the damage and its position were assessed. The damage was numerically simulated by reducing the stiffness of the components.

Different studies on the dynamic buckling induced by impact loading can be found in the literature [24-26]. In [27], the dynamic buckling of an elastic cylindrical shell subjected to axial impact was presented, and the influence of the boundary condition on the critical velocity of the impactor was assessed. In [28], the dynamic pulse buckling of composite laminated beams subjected to impact in the axial direction was investigated. In particular, the influence of different beams parameters (transverse and axial inertias, shear deformation, cross-section's rotational inertia, and axial shortening) on the beams' pulse buckling response was assessed.

Interesting insight on the dynamic instability can be found in [29]. A very detailed study was presented by the authors, which categorized the phenomenon according to the nature of the external load, whose direction can vary depending on the deformation of the structure, classifying the dynamic buckling problems as flutter or pulse buckling. 
In this work, detailed numerical analyses have been presented, aimed to investigate the dynamic buckling response of the composite stanchion, in the finite element code Abaqus environment (release 2019, Dassault Systèmes Simulia Corp: Providence, Rhode Island, RI, SUA). Preliminary finite element models have been presented and compared, considering different in-plane and through-the-thickness element dimensions, different element types, and different material formulations, in order to find the model that more faithfully reproduces the investigated phenomenon. The latter has been used for the subsequent numerical investigation: The static stability limit of the composite stanchion (identified by its static critical buckling load) has been found; then, three different low-frequency cyclic load conditions have been considered (below, close, and above the static critical buckling load). In Section 2, the test cases are described, while in Section 3, the numerical analyses are introduced, including preliminary analyses aimed to determine the most suitable numerical model able to describe the dynamic phenomenon, and the results are critically discussed.

\section{Test Case Description}

The investigated test case, which has been previously validated in [30-32], is representative of the stanchion of the cargo floor of a regional aircraft of general aviation [33]. Images of the stanchions and their location in a typical fuselage section are reported in Figure 1.

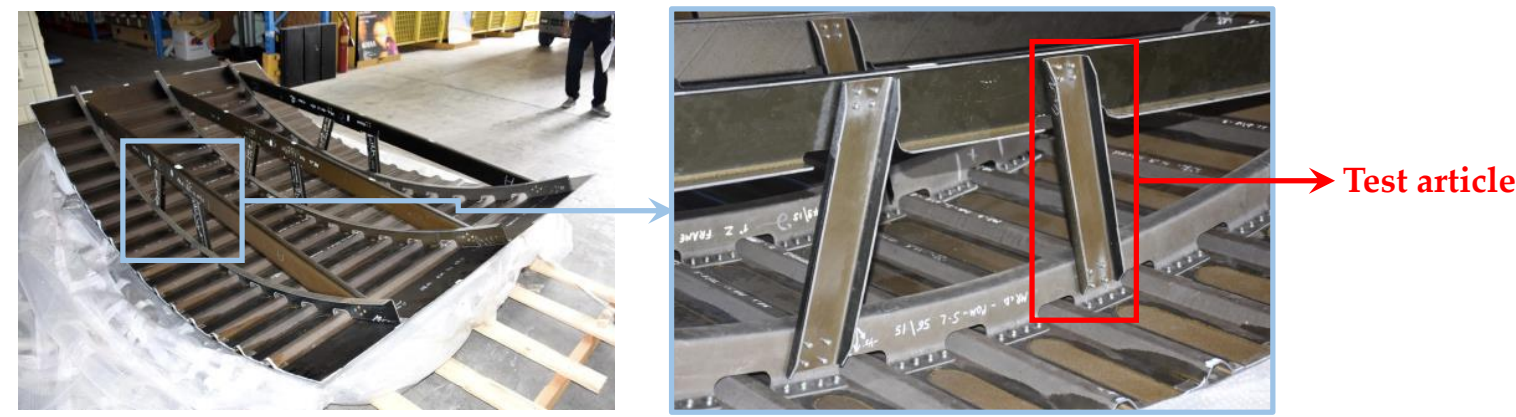

Figure 1. Location of the stanchion in a typical fuselage section.

Two different test articles, with different geometrical characteristics, have been considered. In particular, Test Article 1 is $380 \mathrm{~mm}$ long, while the length of Test Article 2 is $315 \mathrm{~mm}$. More details on the test cases' geometry and boundary conditions can be found in Figure 2. According to Figure 2, both sides of the specimens have been potted. A compressive displacement has been applied on one side, while the opposite side has been fixed.

The stanchion material is a composite made of carbon fibers and epoxy matrix at high polymerization temperature. The mechanical properties of the composite lamina are reported in Table 1, where $\rho$ is the nominal density, th is the lamina thickness, $E$ is Young's modulus, $G$ is the shear modulus, $v$ is Poisson's ratio, $X_{t}$ and $X_{c}$ are respectively the longitudinal tensile and compressive strengths, $Y_{t}$ and $Y_{c}$ are respectively the transversal tensile and compressive strengths, and $\mathrm{S}_{\mathrm{c}}$ is the shear strength. The stacking sequence of the laminate is $[45 ;-45 ; 90 ;-45 ; 45 ; 0 ; 0 ; 0 ; 0 ; 0 ; 45 ;-45 ; 90 ;-45 ; 45]$.

Table 1. Mechanical properties of the lamina.

\begin{tabular}{ccccccccccccc}
\hline $\begin{array}{c}\rho \\
{\left[\mathrm{g} / \mathrm{cm}^{3}\right]}\end{array}$ & $\begin{array}{c}\mathrm{th} \\
{[\mathrm{mm}]}\end{array}$ & $\begin{array}{c}\mathrm{E}_{11} \\
{[\mathrm{MPa}]}\end{array}$ & $\begin{array}{c}\mathrm{E}_{22} \\
{[\mathrm{MPa}]}\end{array}$ & $\begin{array}{c}\mathrm{G}_{12} \\
{[\mathrm{MPa}]}\end{array}$ & $\begin{array}{c}\mathrm{G}_{13} \\
{[\mathrm{MPa}]}\end{array}$ & $\begin{array}{c}\mathrm{G}_{23} \\
{[\mathrm{MPa}]}\end{array}$ & $\begin{array}{c}v_{12} \\
{[-]}\end{array}$ & $\begin{array}{c}\mathbf{X}_{\mathrm{t}} \\
{[\mathrm{MPa}]}\end{array}$ & $\begin{array}{c}\mathbf{X}_{\mathrm{c}} \\
{[\mathrm{MPa}]}\end{array}$ & $\begin{array}{c}\mathrm{Y}_{\mathrm{t}} \\
{[\mathrm{MPa}]}\end{array}$ & $\begin{array}{c}\mathrm{Y}_{\mathbf{c}} \\
{[\mathrm{MPa}]}\end{array}$ & $\begin{array}{c}\mathrm{S}_{\mathrm{c}} \\
{[\mathrm{MPa}]}\end{array}$ \\
\hline 1.6 & 0.186 & 135,000 & 8430 & 4160 & 4160 & 3328 & 0.26 & 2257 & 800 & 75 & 171 & 85 \\
\hline
\end{tabular}


Test Article 1

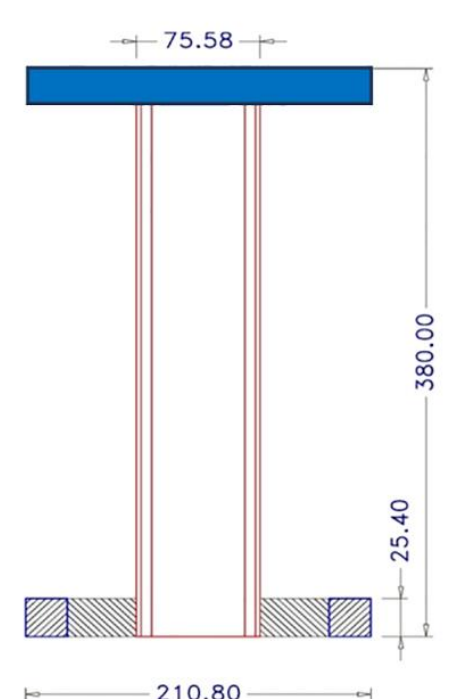

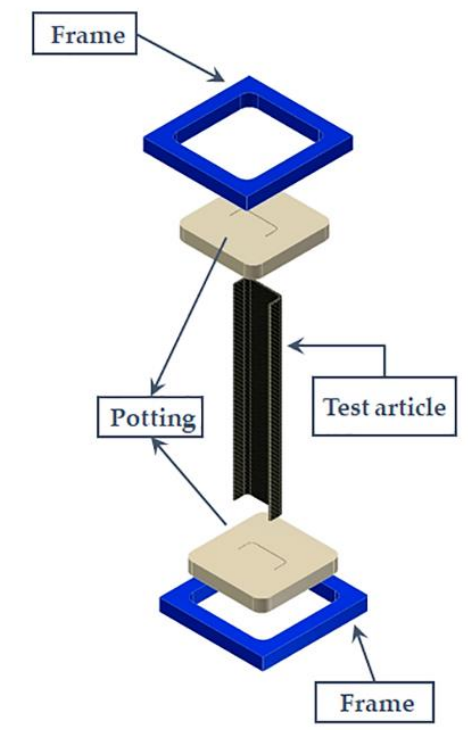

\section{Test Article 2}

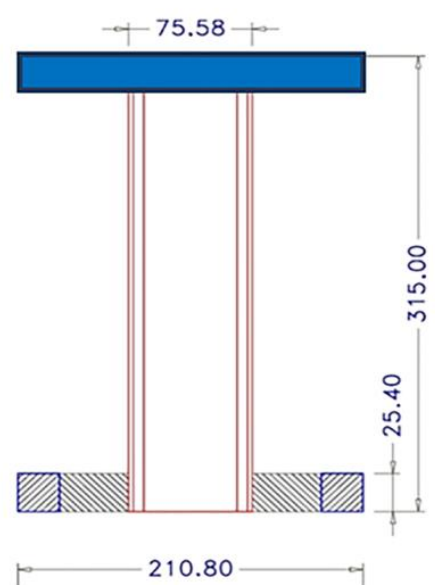

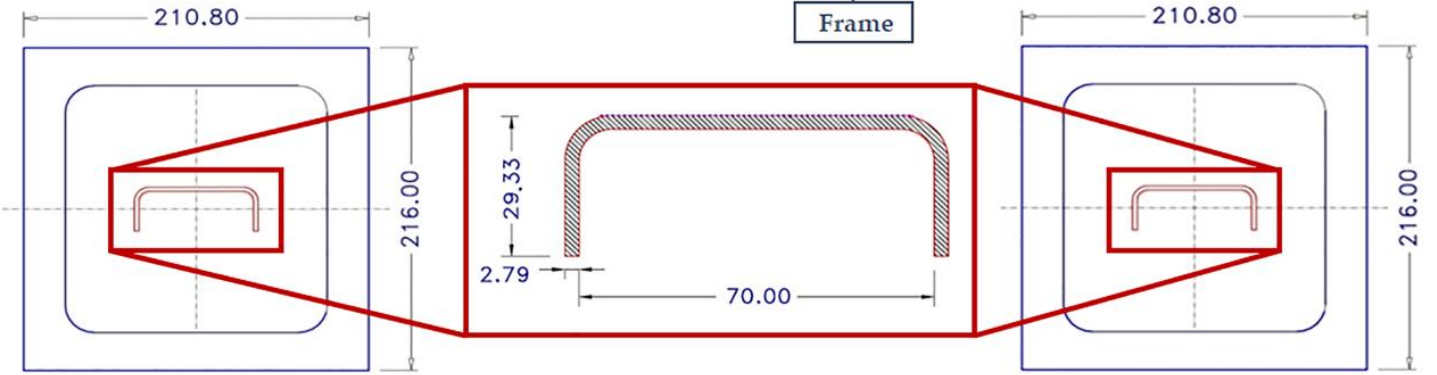

Figure 2. Geometrical description and boundary conditions.

\section{Results and Discussion}

\subsection{Mesh Convergence Analysis}

A preliminary mesh convergence analysis has been carried out to determine the best compromise between computational costs and accuracy of the results in terms of predicted stiffness. Hence, different static linear analyses have been performed, varying the in-plane and through-the-thickness element sizes. In particular, three different mesh element sizes were considered: Coarser $(8 \mathrm{~mm})$, intermediate $(4 \mathrm{~mm})$, and finer $(2 \mathrm{~mm})$. Moreover, for each in-plane element size, three through-the-thickness mesh configurations have been investigated, resulting in the nine mesh configurations that have been analyzed and compared to each other. In particular, Figures 3-5 report the model configuration considering, respectively, one, three, and five elements through the thickness. Eight-node Abaqus Continuum shell elements SC8R [34], with 3 degrees of freedom (DoF) per node and a reduced integration scheme, have been used to discretize the model.

The different composite layups, which depend on the number of elements in the thickness direction, are shown in Figure 6.

A linear static compression test has been performed on the configurations, to compare the results in terms of stiffness and computational time (16-core Intel Xeon E5-2687W 3.10 GHz processor, 64 GB RAM). The results are summarized in Table 2.

According to the results reported in Table 2, the configuration 3B represents the best compromise between accuracy of the results and computational time. Hence, this model will be used in all the subsequent analyses. 


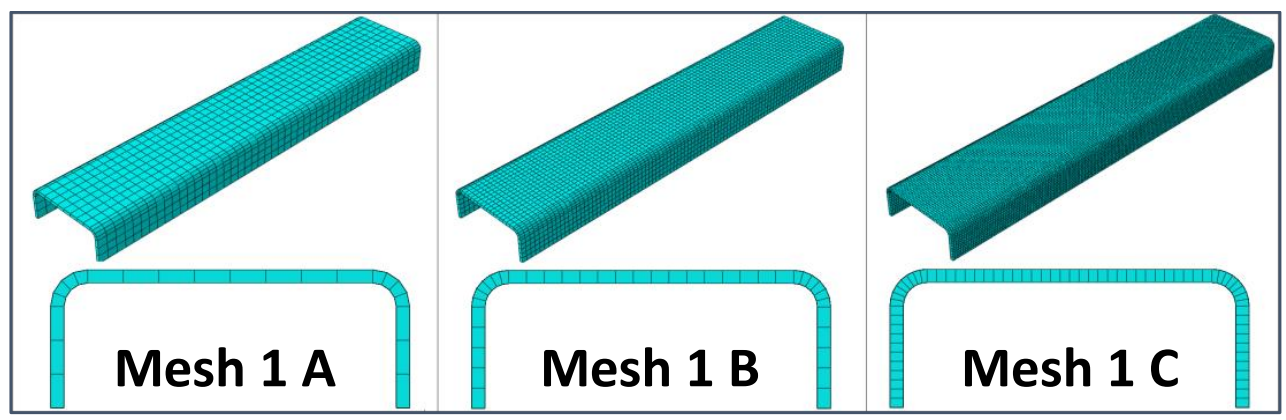

Figure 3. One element in the thickness direction: Coarser mesh (Mesh 1A), intermediate mesh (Mesh 1B), and finer mesh (Mesh 1C).

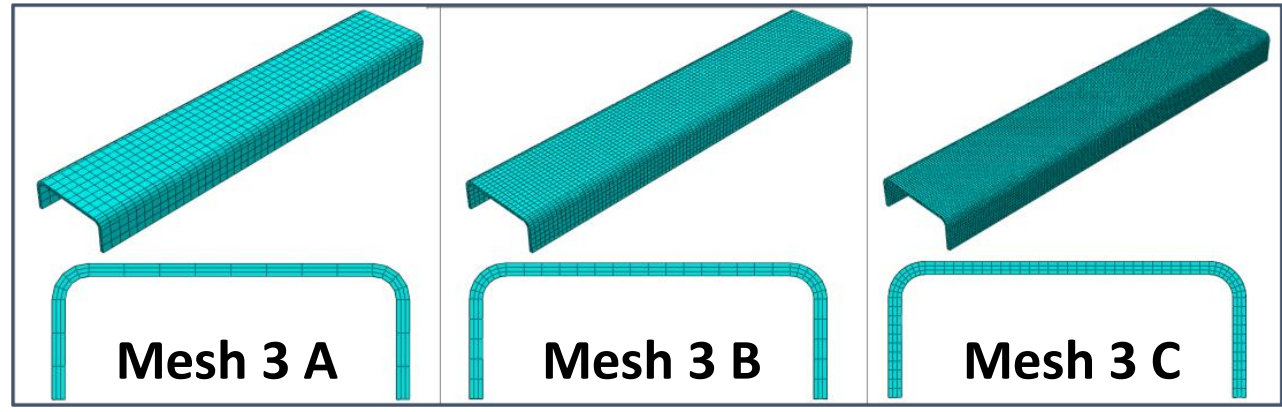

Figure 4. Three elements in the thickness direction: Coarser mesh (Mesh 3A), intermediate mesh (Mesh 3B), and finer mesh (Mesh 3C).

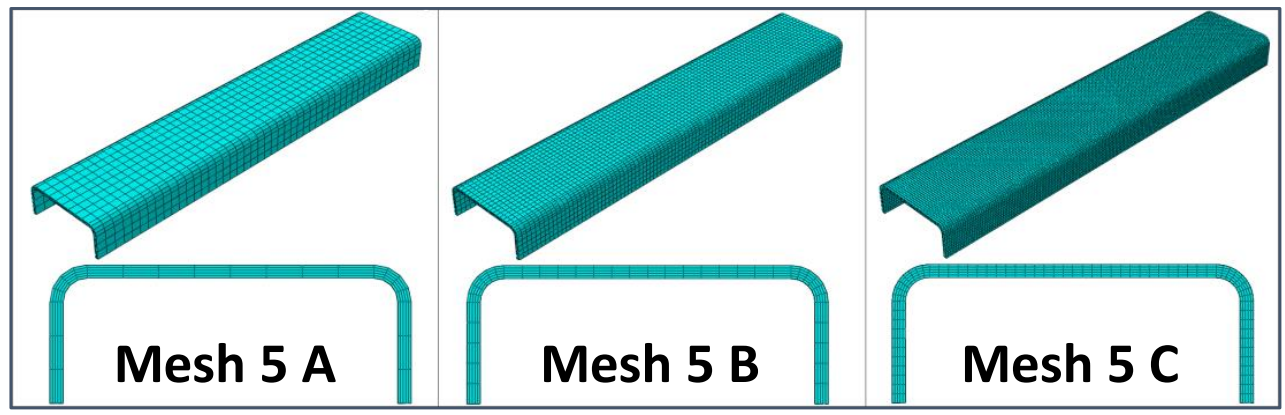

Figure 5. Five elements in the thickness direction: Coarser mesh (Mesh 5A), intermediate mesh (Mesh 5B), and finer mesh (Mesh 5C).

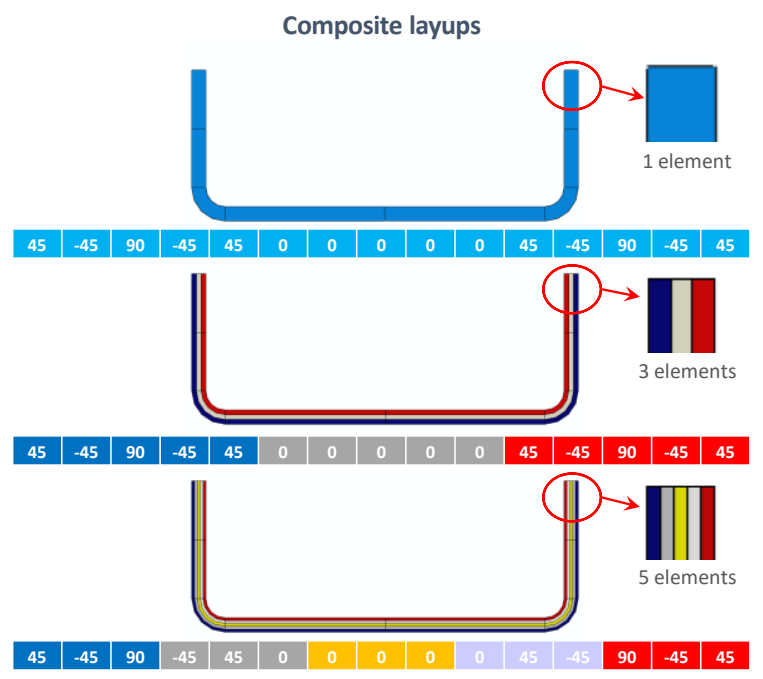

Figure 6. Composite layups. 
Table 2. Mesh convergence analysis results.

\begin{tabular}{cccccc}
\hline $\begin{array}{c}\text { Number of Elements in } \\
\text { the Thickness }\end{array}$ & Element Size & Model Name & $\begin{array}{c}\text { Number of } \\
\text { Elements (Total) }\end{array}$ & $\begin{array}{c}\text { Stiffness } \\
{[\mathbf{k N} / \mathbf{m m}]}\end{array}$ & $\begin{array}{c}\text { Computational } \\
\text { Time }\end{array}$ \\
\hline \multirow{2}{*}{1} & $8 \mathrm{~mm}$ & Mesh 1A & 1056 & 56.220 & $10 \mathrm{~s}$ \\
& $4 \mathrm{~mm}$ & Mesh 1B & 3572 & 56.317 & $15 \mathrm{~s}$ \\
\hline \multirow{2}{*}{3} & $2 \mathrm{~mm}$ & Mesh 1C & 12,920 & 56.340 & $21 \mathrm{~s}$ \\
\hline & $8 \mathrm{~mm}$ & Mesh 3A & 3168 & 56.215 & $13 \mathrm{~s}$ \\
& $4 \mathrm{~mm}$ & Mesh 3B & 10,716 & 56.305 & $18 \mathrm{~s}$ \\
\hline 5 & $2 \mathrm{~mm}$ & Mesh 3C & 38,760 & 56.327 & $33 \mathrm{~s}$ \\
\hline & $8 \mathrm{~mm}$ & Mesh 5A & 5280 & 56.097 & $16 \mathrm{~s}$ \\
& $4 \mathrm{~mm}$ & Mesh 5B & 17,860 & 56.180 & $21 \mathrm{~s}$ \\
\hline
\end{tabular}

\subsection{Validation of the Numerical Model}

The selected numerical model has been validated by comparison with experimental test campaign results, in terms of stiffness and failure. In particular, two experimental tests have been performed:

- Experimental Test T1: Compressive test aimed to determine the stiffness of the structure;

- Experimental Test T2: Compressive test up to the total failure.

In Figure 7 and Table 3, it is possible to appreciate the good agreement between the numerical predicted solutions and the results of the experimental campaign tests in terms of stiffness and failure load. Moreover, the failure mode of the test article, computed by using the Hashin's failure criteria, has also been predicted with a high level of accuracy, as highlighted in Figure 8. No buckling phenomena occur up to the failure load both experimentally and numerically.
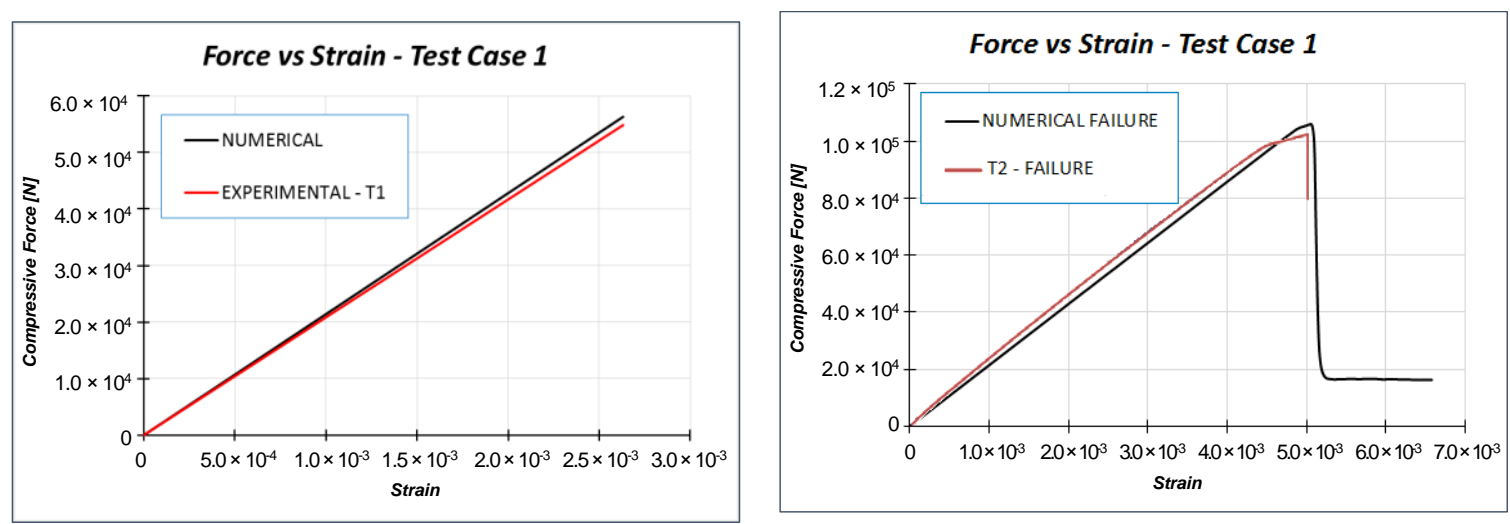

Figure 7. Numerical-experimental comparisons: Load vs. strain.
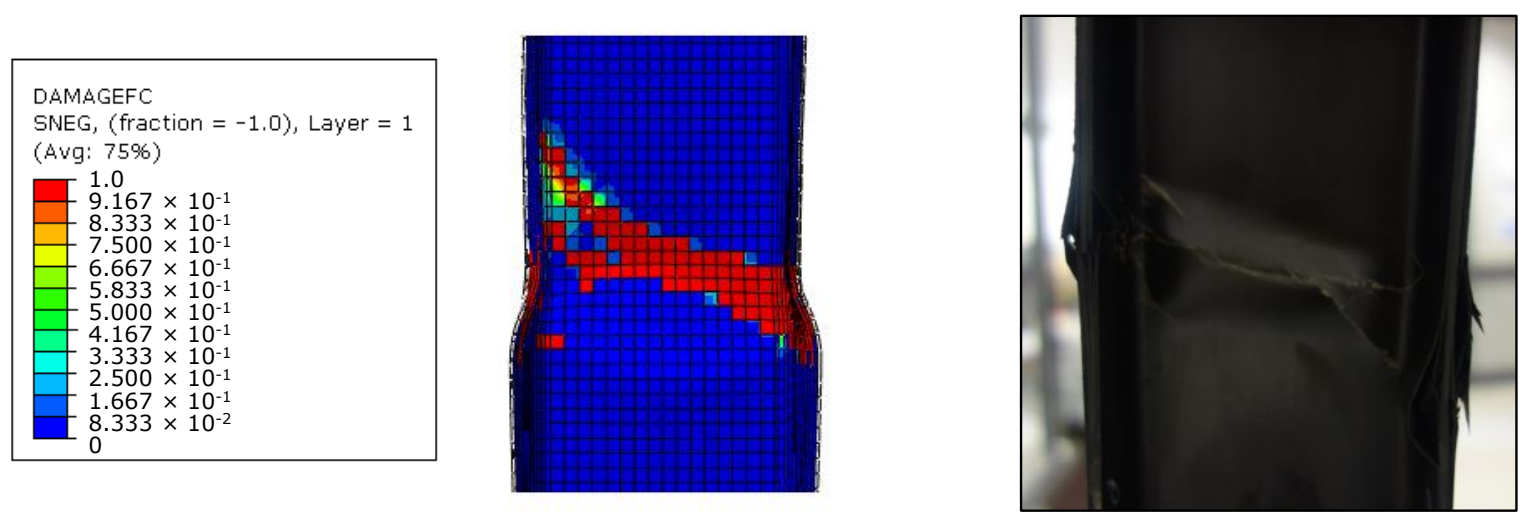

Figure 8. Numerical-experimental comparisons: Failures. 
Table 3. Numerical-experimental comparisons: Stiffness and failure load.

\begin{tabular}{lcc}
\hline & Stiffness & Failure Load \\
\hline Experimental & $54.8 \mathrm{kN} / \mathrm{mm}$ & $103.7 \mathrm{kN}$ \\
Numerical & $56.3 \mathrm{kN} / \mathrm{mm}$ & $106.0 \mathrm{kN}$ \\
Error & $2.6 \%$ & $2.2 \%$ \\
\hline
\end{tabular}

\subsection{Dynamic Buckling Analysis}

Once the numerical model has been validated, explicit numerical analyses [35,36] have been performed on Test Case 2 to investigate the arising of the dynamic buckling phenomenon. However, as a preliminary step, compressive tests have been performed on Test Case 2 by using implicit and explicit formulations, and the results have been compared in order to assess the robustness of the numerical model and the influence of the solver's scheme. Experimental data are available only for quasi-static loading conditions and, therefore, for implicit solutions. As the numerical investigations presented in the next sections have been performed with an explicit solver, the implicit-explicit comparison aims to investigate the possible influence of the solution scheme on the results. In the explicit analysis, the load is applied by a smoothed step in order to minimize the inertial effect (related to dynamic simulation). Thus, no significant differences are expected; anyway, in order to highlight this aspect, the implicit-explicit comparison is presented, to demonstrate that differences in structural response, in the explicit model, are related only to different loading conditions and cannot be addressed to the adopted solution scheme. Both models were discretized by means of continuum shell elements (SC8R). All explicit analyses have been performed setting a structural damping equal to $2 \%$. Good agreement has been found between the solutions of both formulations, as confirmed by the load-strain chart in Figure 9, the element failures in Figure 10, and the failure displacements and loads in Table 4.

According to Figures 9 and 10, no relevant differences between the implicit and explicit solution can be found. The slight deviation in the failure path is related to small differences in the load distribution, due to the difference in the calculation of nodal displacements and forces between the two solution schemes. Indeed, the results must not be focused on the number of failed elements (Figure 10) but, instead, on the global behavior, which is reported in the graph of Figure 9. The buckling load of the structure is very close to the failure load, so no post-buckling regime is expected. The slight deviation between the two curves (at about $3.0 \times 10^{-3}$ strain) is related to the damage propagation, not to the post-buckling regime. In the explicit analysis, the elements reach the total failure state faster with respect to the implicit one, leading to an earlier and smaller loss in stiffness.

Table 4. Implicit-explicit formulation comparisons: Failure displacement and failure load.

\begin{tabular}{lll}
\hline & Failure Displacement & Failure Load \\
\hline Implicit & $1.59 \mathrm{~mm}$ & $107.3 \mathrm{kN}$ \\
Explicit & $1.60 \mathrm{~mm}$ & $104.0 \mathrm{kN}$ \\
Error & $0.06 \%$ & $3.1 \%$ \\
\hline
\end{tabular}

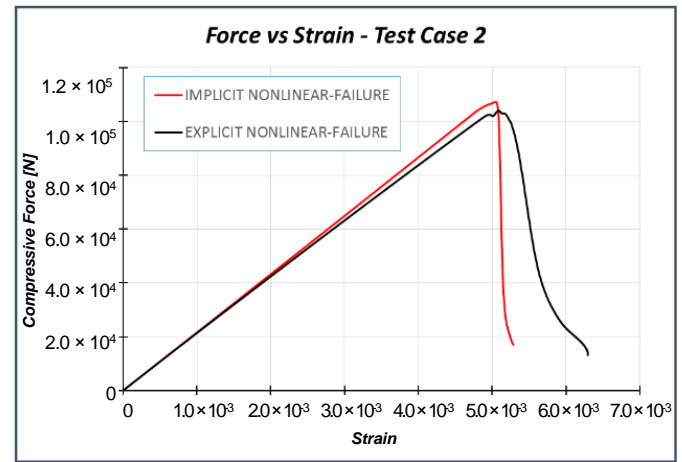

Figure 9. Implicit-explicit formulation comparisons: Load vs. strain. 

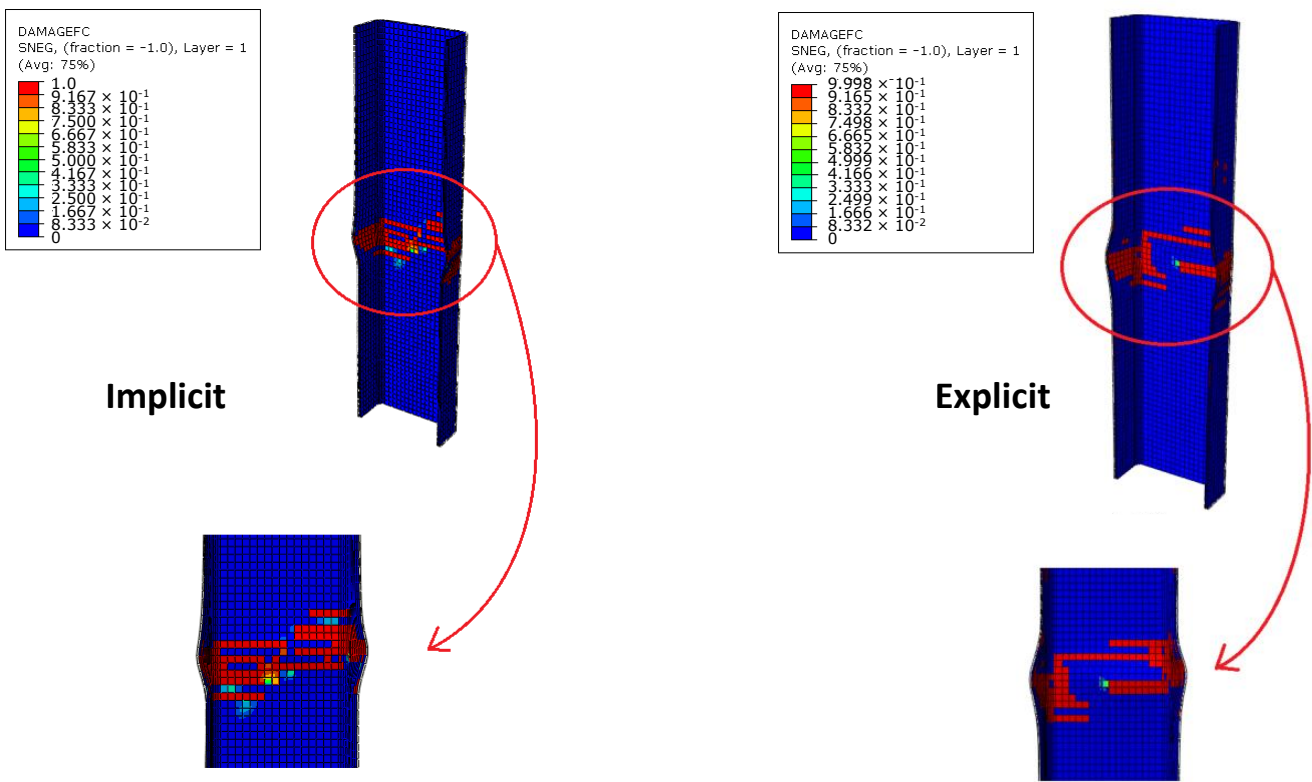

Figure 10. Implicit-explicit formulation comparisons: Failures.

In the dynamic explicit analyses, a rigid plate has been used to apply the time-dependent load onto the structure as a controlled displacement, as shown in Figure 11, which reports the control points where the outputs have been monitored as well. Seventy-two control points have been used to evaluate the occurrence of the buckling phenomena; they are placed along the entire stanchion and in a different section location in the back-to-back configuration.

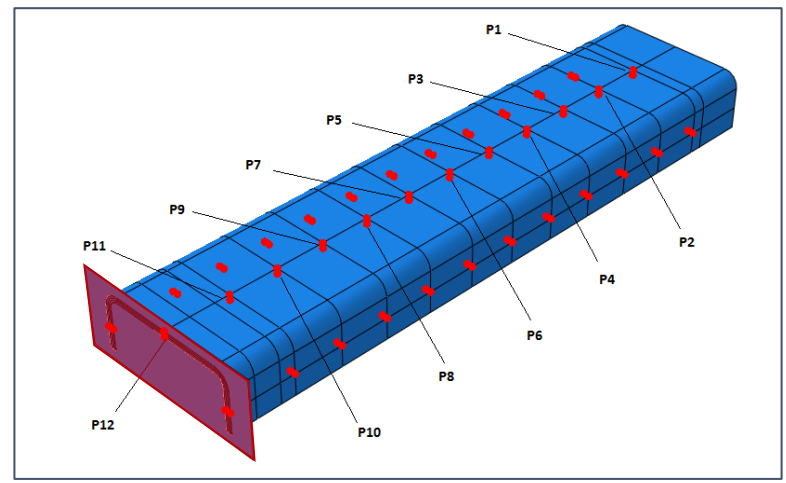

Figure 11. Explicit analysis: Rigid plate and control points.

Furthermore, several numerical element formulations have been investigated, to assess the capability of different numerical formulations to simulate the dynamic phenomenon. Hence, alongside the aforementioned continuum shell (SC8R) element discretization with three elements in the thickness direction (Model 3B), the following models, summarized in Table 5, have been introduced:

- $\quad$ Model S: This model has been discretized by using four-node linear shell (S4) elements [34]. The same in-plane element size of Model 3B has been considered; however, obviously, no division in the thickness direction has been employed. The equivalent properties of the entire laminate, reported in Table 6, have been used for each element.

- Model 1R: This model has been discretized by using eight-node linear solid elements with a reduced integration scheme (C3D8R) [34]. The same in-plane mesh discretization used for Model $3 \mathrm{~B}$ and Model $\mathrm{S}$ has been considered. One element has been placed in the thickness direction, in order to avoid the use of the layered option. The equivalent mechanical properties of the entire laminate (Table 6) have been assigned to the elements. 
- Model3R: This model is similar to model 1R but differs from the latter as three elements in the thickness direction have been considered. Hence, the properties of the equivalent five-plies sublaminates corresponding to those shown in Figure 6 (Table 7) have been properly assigned to each element.

Table 5. Investigated element formulations.

\begin{tabular}{llcl}
\hline Model Name & Element Type & \# of Elements in the Thickness & Laminate Type \\
\hline Model 3B & Continuum Shell (SC8R) & 3 & Composite Layup \\
Model S & Shell (S4) & 1 & Composite Layup \\
Model 1R & 3D Stress (C3D8R) & 1 & Equivalent Laminate \\
Model 3R & 3D Stress (C3D8R) & 3 & Equivalent Laminate \\
\hline
\end{tabular}

Table 6. Equivalent laminate mechanical properties.

\begin{tabular}{cccccccc}
\hline th $[\mathrm{mm}]$ & $\mathrm{E}_{\mathbf{1 1}}[\mathrm{MPa}]$ & $\mathrm{E}_{\mathbf{2 2}}[\mathrm{MPa}]$ & $\mathrm{E}_{\mathbf{3 3}}[\mathrm{MPa}]$ & $\mathrm{G}_{\mathbf{1 2}}[\mathrm{MPa}]$ & $\mathrm{G}_{\mathbf{1 3}}[\mathrm{MPa}]$ & $\mathrm{G}_{\mathbf{2 3}}[\mathrm{MPa}]$ & $\boldsymbol{v}_{\mathbf{1 2}}[-]$ \\
\hline 2.79 & 60,267 & 37,845 & 8430 & 20,559 & 20,559 & 3328 & 0.43 \\
\hline
\end{tabular}

Table 7. Equivalent sublaminate mechanical properties.

\begin{tabular}{ccccccccccc}
\hline Stacking Sequence & $\begin{array}{c}\mathrm{th} \\
{[\mathbf{m m}]}\end{array}$ & $\begin{array}{c}\mathbf{E}_{\mathbf{1 1}} \\
{[\mathrm{MPa}]}\end{array}$ & $\begin{array}{c}\mathbf{E}_{\mathbf{2 2}} \\
{[\mathbf{M P a}]}\end{array}$ & $\begin{array}{c}\mathbf{E}_{\mathbf{3 3}} \\
{[\mathrm{MPa}]}\end{array}$ & $\begin{array}{c}\mathbf{G}_{\mathbf{1 2}} \\
{[\mathrm{MPa}]}\end{array}$ & $\begin{array}{c}\mathbf{G}_{\mathbf{1 3}} \\
{[\mathbf{M P a}]}\end{array}$ & $\begin{array}{c}\mathbf{G}_{\mathbf{2 3}} \\
{[\mathbf{M P a}]}\end{array}$ & $\begin{array}{c}\boldsymbol{v}_{\mathbf{1 2}} \\
{[-]}\end{array}$ & $\begin{array}{c}\boldsymbol{v}_{\mathbf{1 3}} \\
{[-]}\end{array}$ & $\begin{array}{c}\boldsymbol{v}_{\mathbf{2 3}} \\
{[-]}\end{array}$ \\
\hline$[0]_{5}$ & 0.93 & 135,000 & 8430 & 8430 & 4160 & 4160 & 3328 & 0.26 & 0.3 & 0.3 \\
{$[-45,45,90,45,-45]$} & 0.93 & 22,674 & 39,437 & 8430 & 28,759 & 28,759 & 3328 & 0.44 & 0.3 & 0.3 \\
\hline
\end{tabular}

The numerical models have been subjected to a triangular load with a maximum compressive amplitude equal to $0.75 \mathrm{~mm}$ (smaller than critical displacement estimated by numerical analysis, which is about $1.53 \mathrm{~mm}$ ), shown in Figure 12. Then, the numerical models have been compared in terms of the free side displacements and fixed side reactions reported in Figure 13.

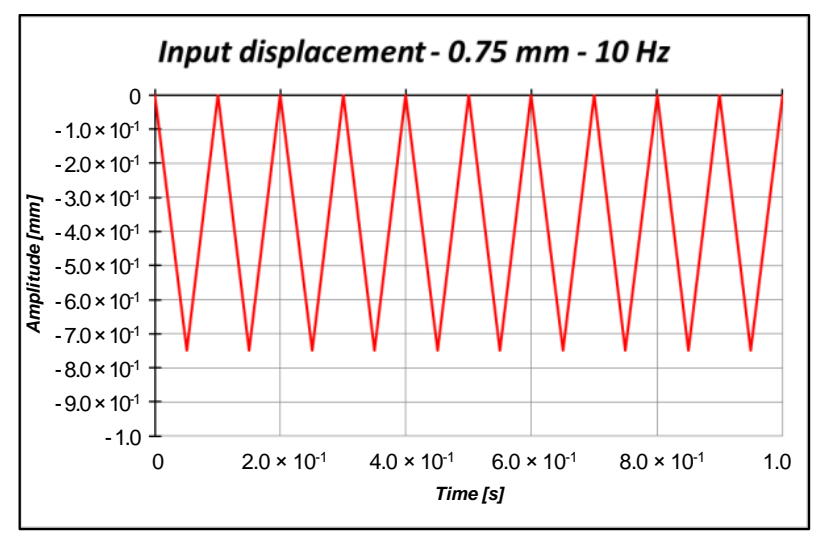

Figure 12. Input triangular displacement.
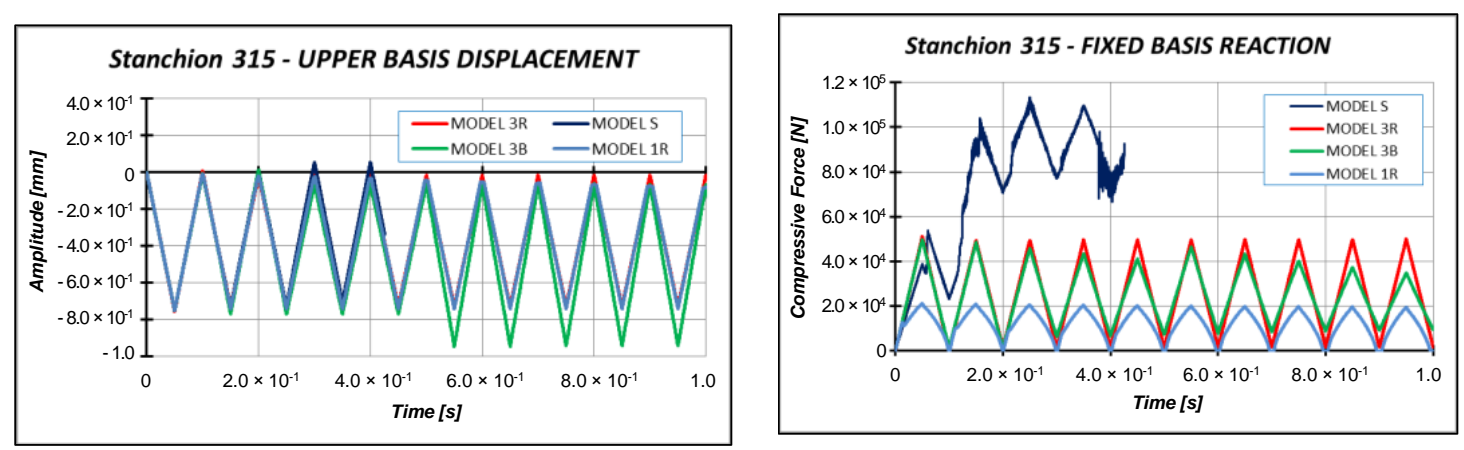

Figure 13. Free side displacement and fixed side reaction comparisons. 
The results reported in Figure 13 demonstrated that the most suitable numerical model able to simulate a dynamic compressive analysis is model 3R, which has been selected in the subsequent analyses. Indeed, in model 3B, the displacement of the specimen is equal to the compressive displacement imposed on the plate only in the initial stage of the load cycle, up to $t=0.25 \mathrm{~s}$. Then, the displacements start to differ from each other. This phenomenon is even more clear starting from $\mathrm{t}=0.5 \mathrm{~s}$. Moreover, the specimen discretized by model 3B is not able to completely be unloaded after $0.2 \mathrm{~s}$, according to the results of the fixed side reaction. Model S experienced convergence issues, as highlighted by the results in terms of fixed side reactions, which are very irregular. Model $1 \mathrm{R}$ experiences issues in terms of free side displacement very similar to those encountered by Model 3B. Moreover, Model 1R is strongly affected by hourglass, as highlighted by fixed side reactions.

Sinusoidal cyclic displacements have then been applied on model 3R. According to preliminary eigenvalue buckling analyses, not reported here for the sake of brevity, the critical Test Case 2 displacement is $1.53 \mathrm{~mm}$. Hence, three input displacements, characterized by a sinusoidal shape with a $10 \mathrm{~Hz}$ frequency, have been considered:

- $\quad$ Applied displacement $=1.0 \mathrm{~mm}$ (below the critical displacement);

- $\quad$ Applied displacement $=1.53 \mathrm{~mm}$ (equal to the critical displacement);

- $\quad$ Applied displacement $=2.0 \mathrm{~mm}$ (above the critical displacement).

Figures 14-16 report the displacements, the reactions, and the energies, as a function of time, for each load case.

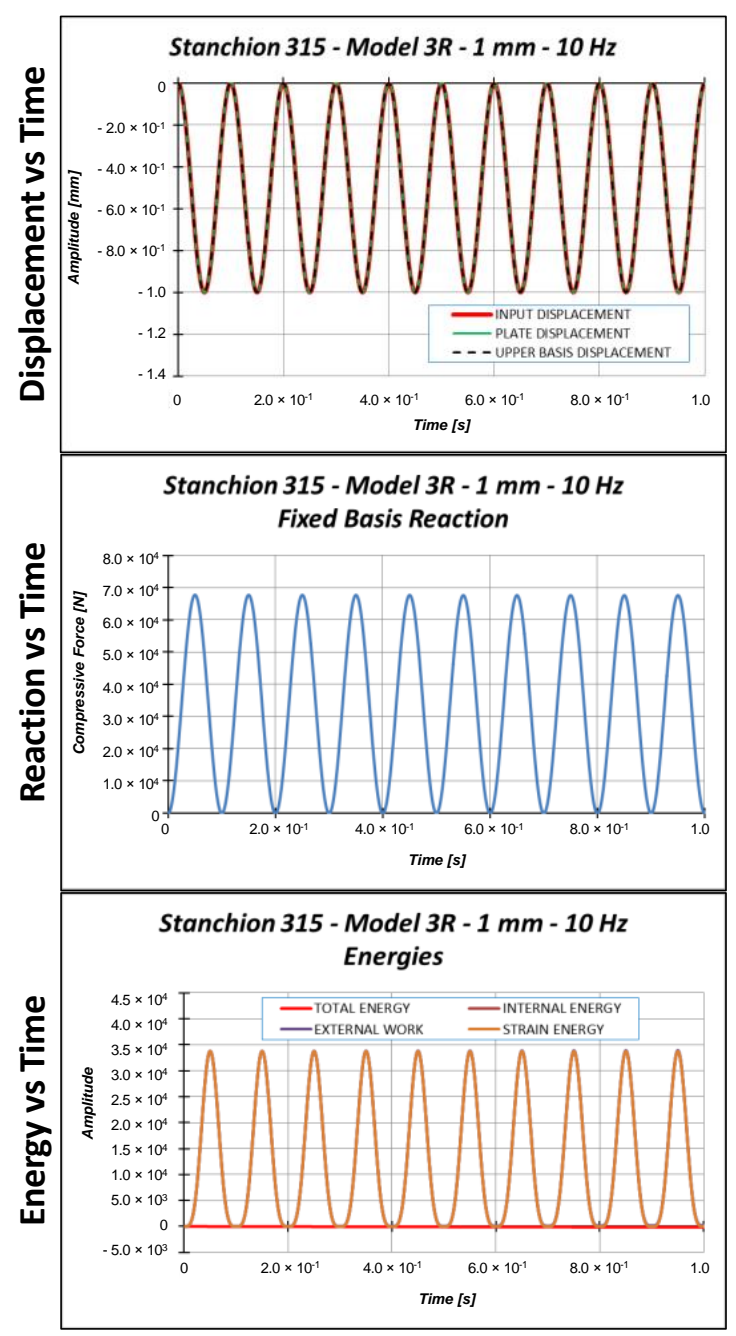

Figure 14. Displacement, reaction, and energies as a function of time: $1.0 \mathrm{~mm}$ applied displacement. 


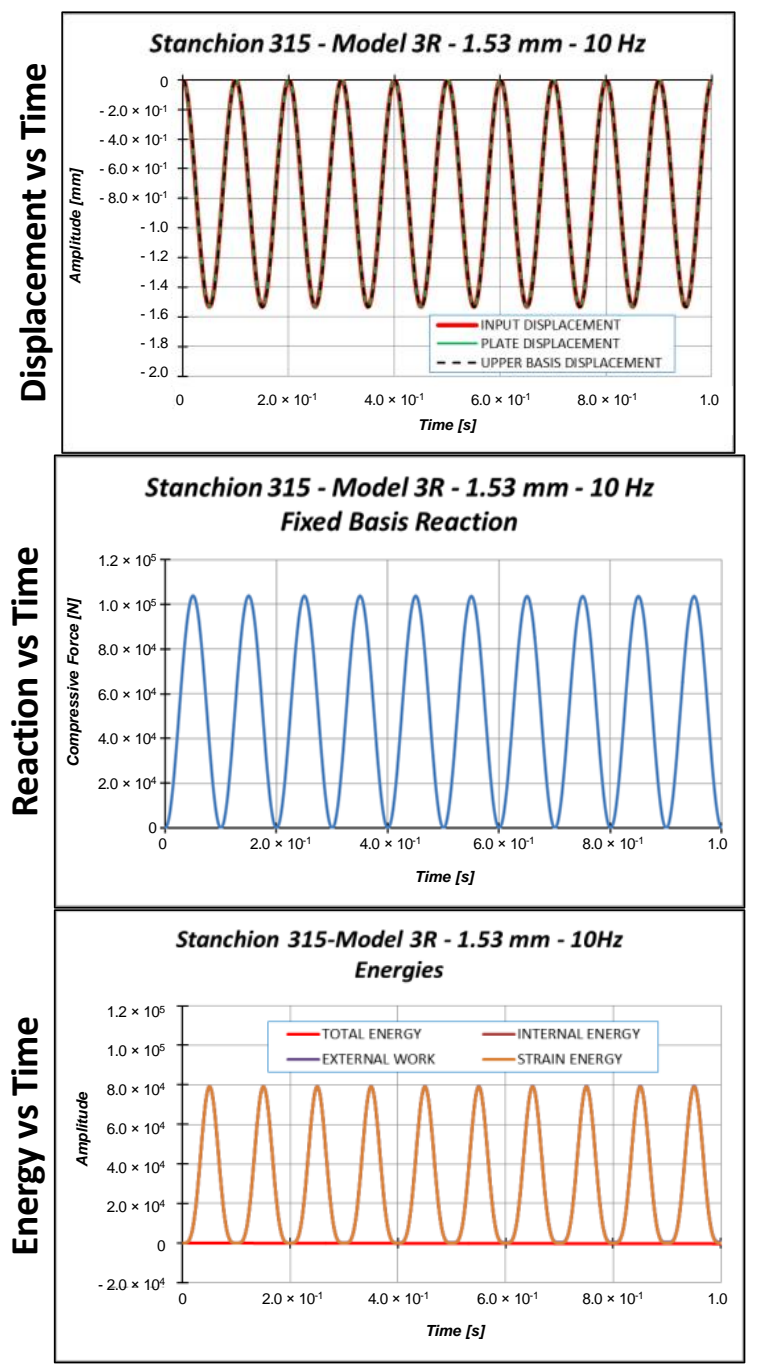

Figure 15. Displacement, reaction, and energies as a function of time: $1.53 \mathrm{~mm}$ applied displacement.

More detailed information on the dynamic behavior of the investigated test case can be obtained from Figure 17, which compares the stiffness corresponding to each load amplitude.

According to Figure 17, the stiffness of the model loaded by a maximum displacement equal to $1 \mathrm{~mm}$ is almost constant, meaning that no buckling occurs. The stiffness of the specimen loaded with a maximum amplitude equal to $1.53 \mathrm{~mm}$ (static buckling load) experiences a clear variation in correspondence to the maximum compression. However, this variation is almost instantaneous; hence, it cannot be considered representative of the buckling phenomenon. These considerations cannot be drawn for the $2 \mathrm{~mm}$ applied displacement. Indeed, in this last load case, the stiffness variation is more pronounced and lasts longer in time. Considering the provided results, it is quite clear that the applied load velocity (about $2 \times$ maximum displacement $\times$ frequency) is too small to generate any resonance issue, which could lead to instability phenomena. Further, a constant structural damping $(0.2 \%)$ has been adopted; hence, small slowdown effects on the elastic wave propagation can be observed with respect to the quasi-static case.

Other information can be taken considering the out-of-plane displacements $\mathrm{U} 2$ of the central points of the specimen (points P3, P6, and P9 in Figure 11), reported in Figures 18-20. 


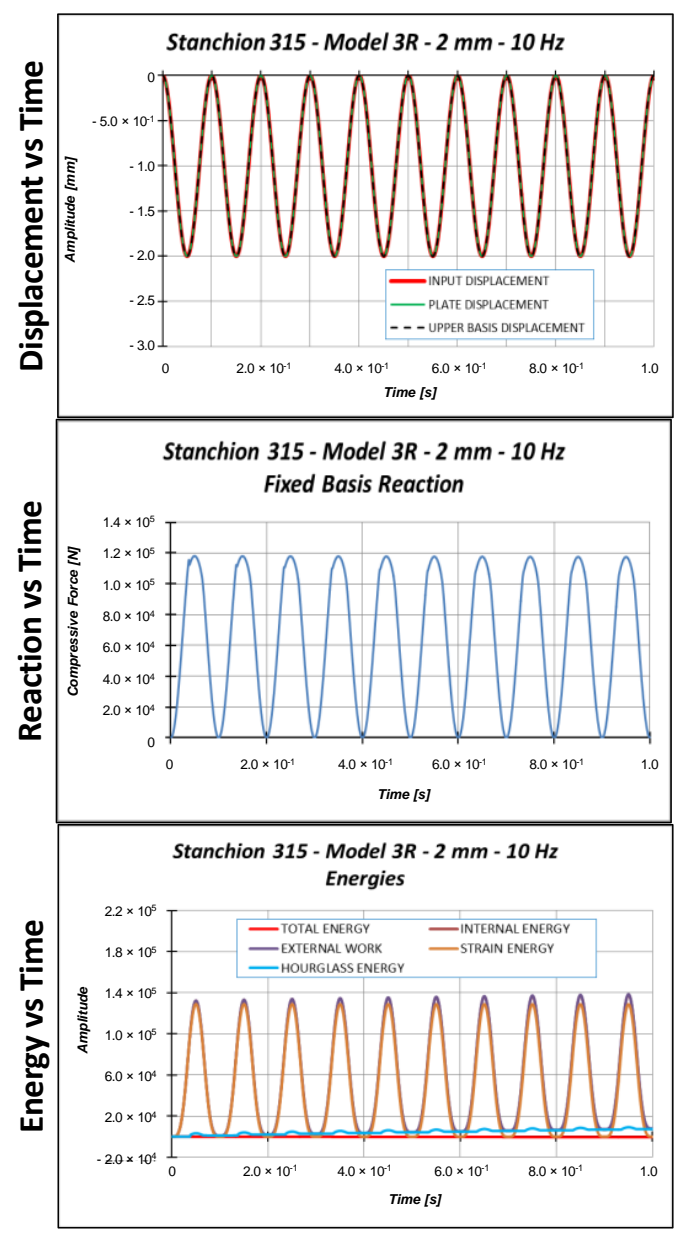

Figure 16. Displacement, reaction, and energies as a function of time: $2.0 \mathrm{~mm}$ applied displacement.
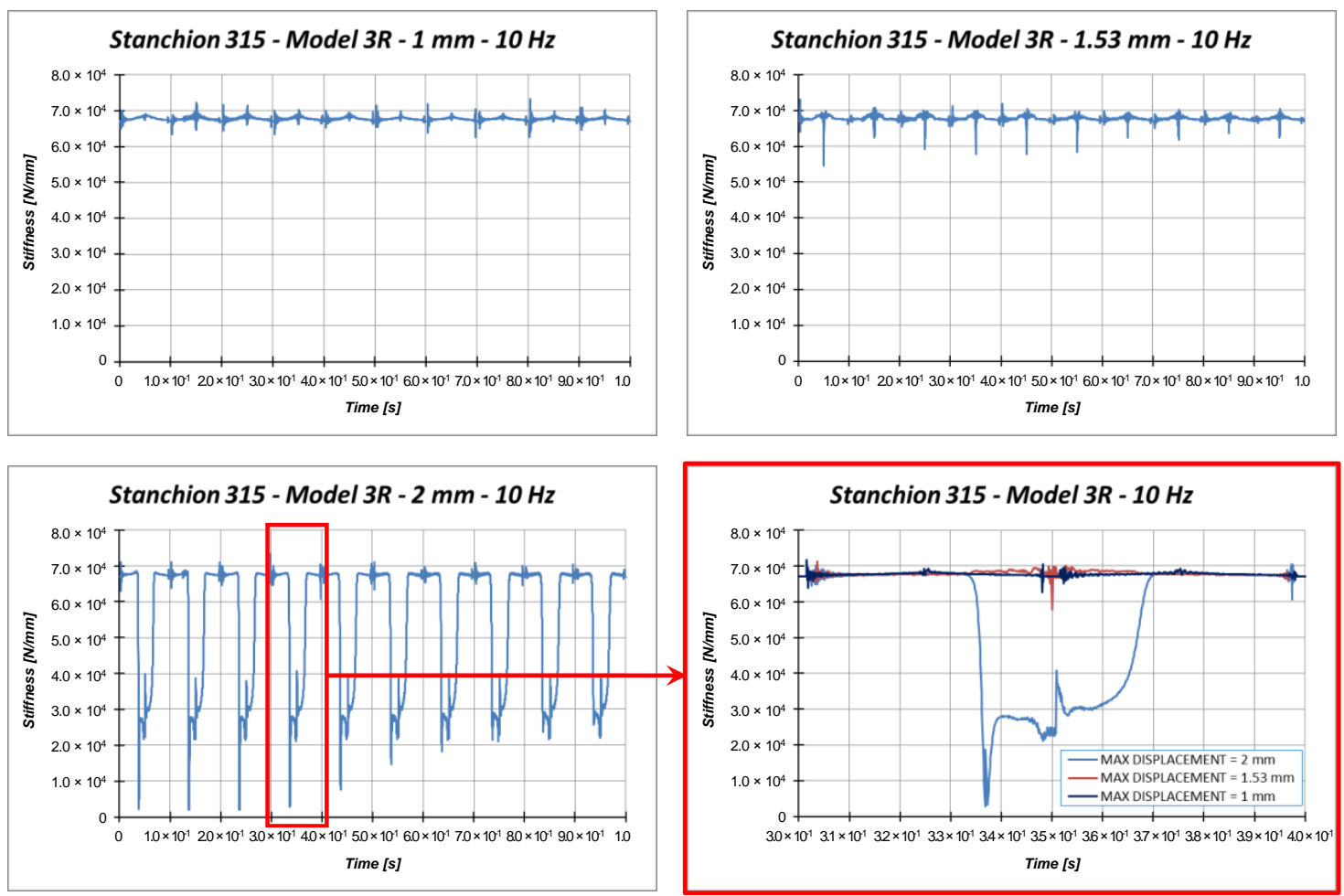

Figure 17. Model 3R: Stiffness comparisons. 

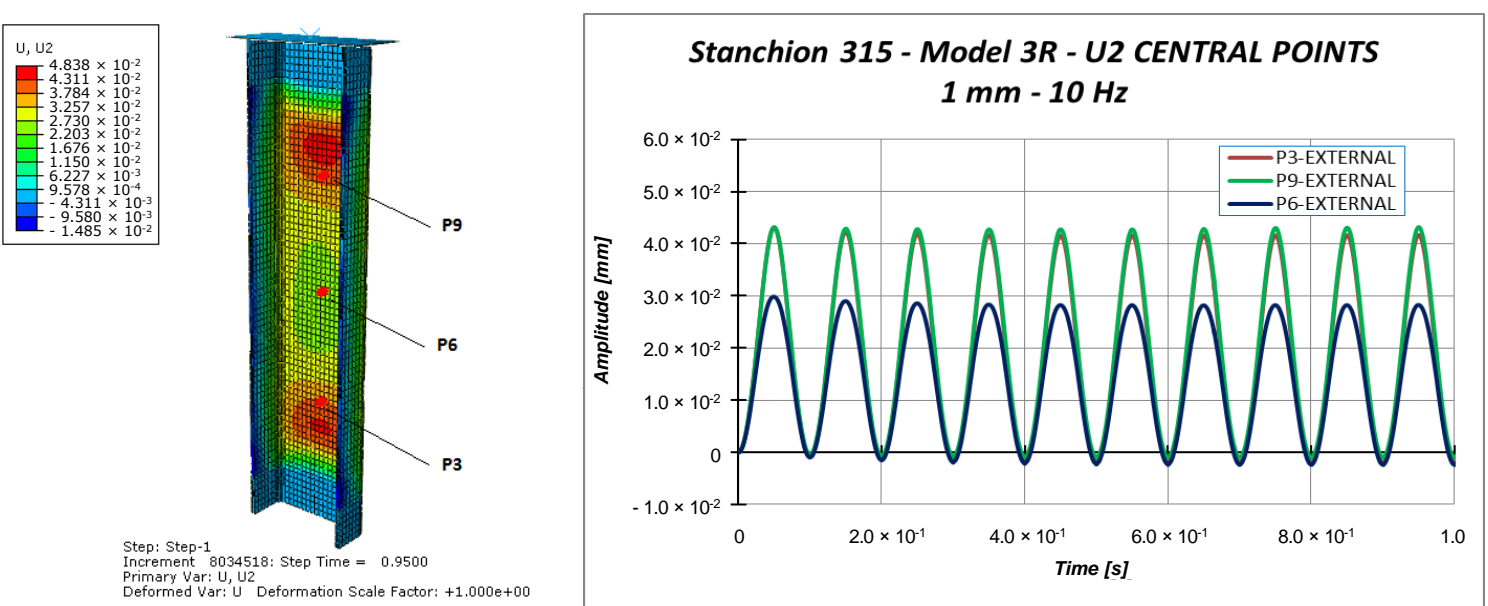

Figure 18. Out-of-plane displacement: $1.0 \mathrm{~mm}$ applied displacement.
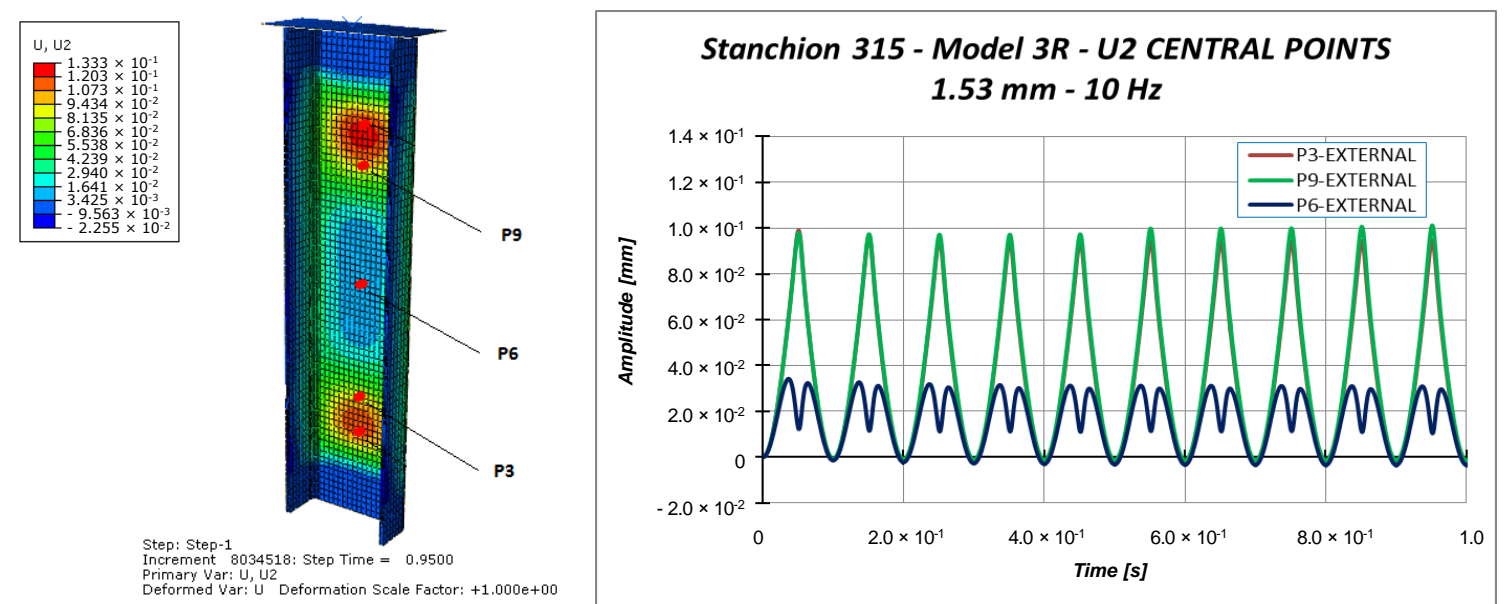

Figure 19. Out-of-plane displacement: $1.53 \mathrm{~mm}$ applied displacement.
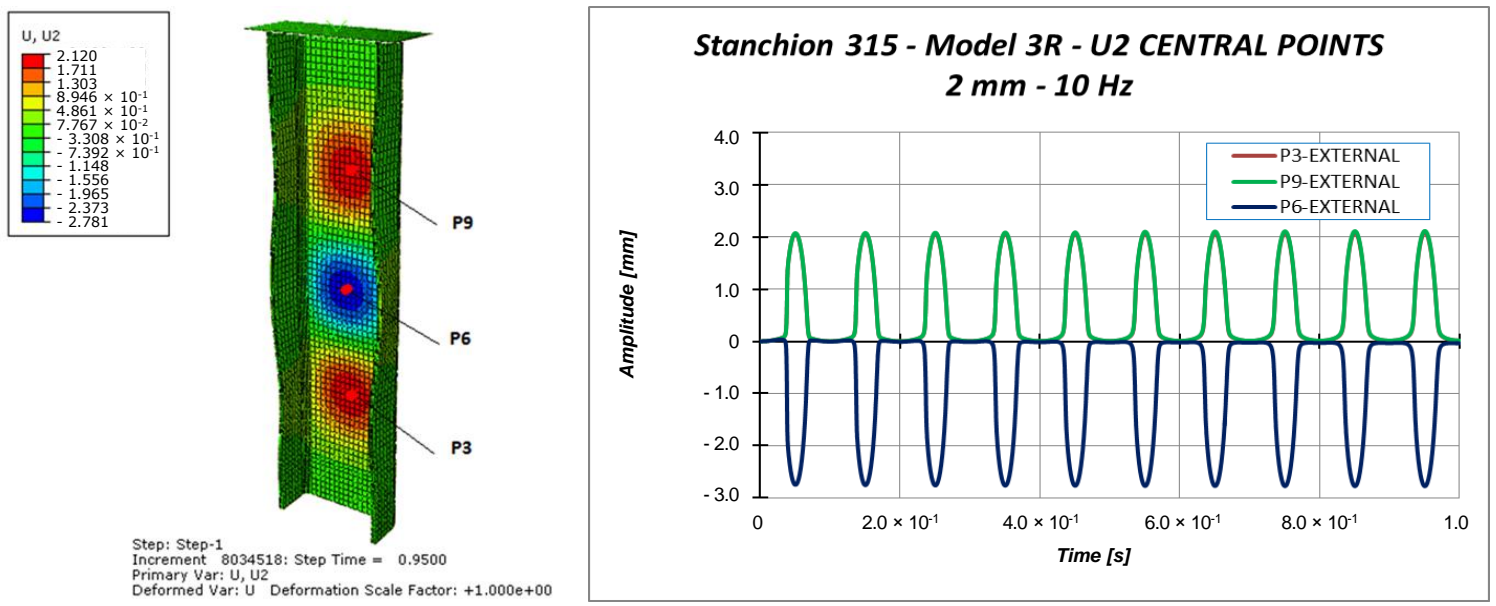

Figure 20. Out-of-plane displacement: $2.0 \mathrm{~mm}$ applied displacement.

Indeed, Figures 18-20 highlight the symmetrical out-of-plane displacement patterns resulting from the structural response of these symmetric systems (due to the adopted material formulation), as suggested in [37].

Considering a maximum applied displacement equal to $1 \mathrm{~mm}$ (Figure 18), no buckling occurs and all the points experience minimal out-of-plane displacements, which follows a sinusoidal and 
regular behavior. In the case of $1.53 \mathrm{~mm}$ maximum applied displacement (Figure 19), a more irregular sinusoidal behavior can be observed. Moreover, point P6 experiences a double peak, corresponding to the maximum compressive displacement, which can be considered representative of the buckling onset. Figure 20 reports the out-of-plane displacements in the case of $2 \mathrm{~mm}$ compression. In this case, point P6 experiences a shift in the value of the displacement, due to the buckling. This can be confirmed by monitoring the strains of the internal and external points considering a maximum applied displacement of $1.53 \mathrm{~mm}$ (Figure 21) and $2.0 \mathrm{~mm}$ (Figure 22).

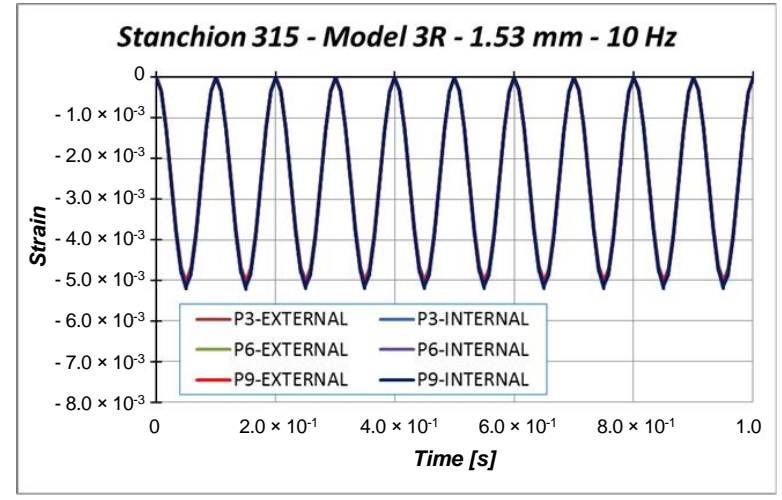

Figure 21. Strain: $1.53 \mathrm{~mm}$ applied displacement.
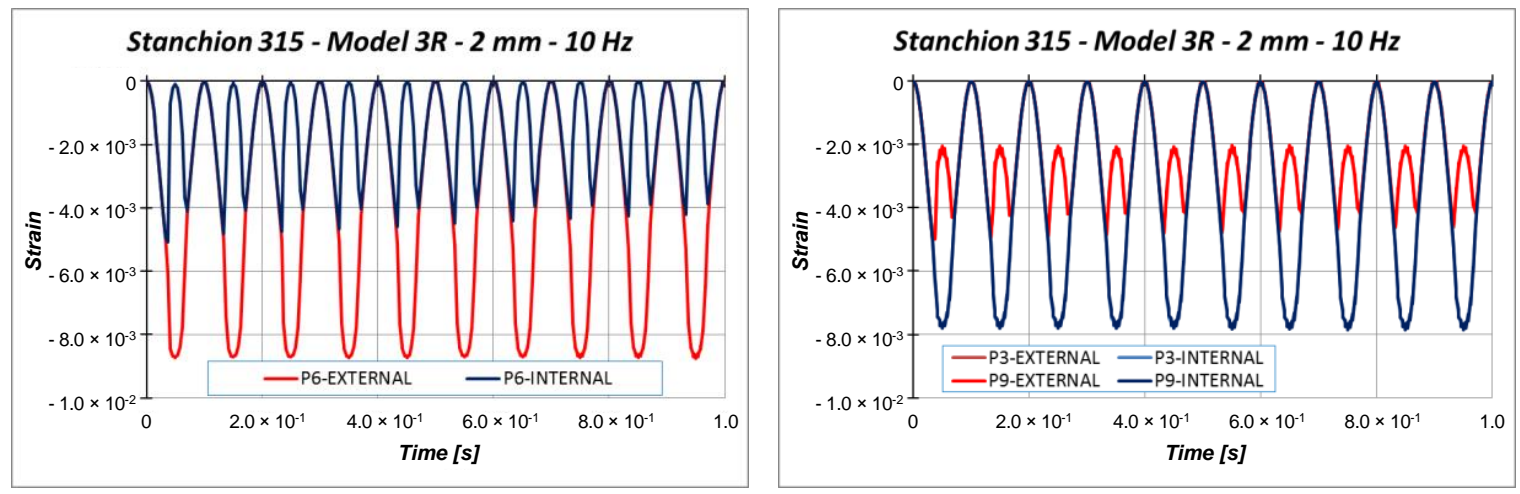

Figure 22. Strain: $2.0 \mathrm{~mm}$ applied displacement.

Indeed, the strains in Figure 21 are almost coincident, proving that compressive strain is mainly due to the compressive applied displacement and is not representative of the buckling phenomenon. On the other side, Figure 22 shows that the external point P6 experiences a compressive strain variation, while the internal point P6 experiences a tensile strain variation, which clearly indicated that buckling occurs. The strains' divergence (outer/inner control point), which indicates the buckling onset, occurs at $76.6 \%$ of the maximum amplitude, which corresponds to a displacement very close to the critical one. Further, with the increment in cycles, the structural behavior is very repetitive, but it is possible to see a small and slow reduction in the critical displacement.

\section{Conclusions}

In this work, the structural behavior of a composite floor beam subjected to cyclical low-frequency compressive loads has been presented. Sensitivity analyses have been carried out in order to find the most suitable numerical model able to simulate the dynamic analyses, considering different mesh discretization, element, and section formulations. The numerical model has been validated with respect to experimental data obtained under quasi-static loading conditions, thus adopting the implicit formulation. In order to investigate the influence of the solution scheme on the numerical results, an explicit-implicit comparison has been performed. The results highlighted that the adopted technique (smoothed step) allows us to 
minimize the inertial effects and, thus, to have a good agreement between the two solver schemes. Therefore, the explicit model can also be considered indirectly validated. Further, considering that the applied loading velocity, in dynamic cyclic loading conditions, is very small (lower than $0.1 \mathrm{~m} / \mathrm{s}$ ), the previous consideration can be extended to the final model.

Explicit non-linear analyses have been performed, applying dynamic $10 \mathrm{~Hz}$ frequency compressive loads. Load cycles with different amplitudes have been considered: $1 \mathrm{~mm}$ (about $70 \%$ of the static buckling value), $1.53 \mathrm{~mm}$ (close to the static buckling value), and finally $2 \mathrm{~mm}$ (above the static buckling value).

The results showed that low-frequency cyclic loads (compared to the test article's own frequencies, that are in the order of hundreds $\mathrm{Hz}$ ) with peak values lower than the static buckling load value are not capable of triggering significant instability. This behavior is confirmed by comparing the stiffness of the models as a function of time for the different load levels applied at the same $10 \mathrm{~Hz}$ frequency.

In particular, all reported results highlight that the applied load velocity (obtained from the load frequency) is small enough to not generate any resonance issue; therefore, the deformation elastic wave is able to cover the entire specimen length in a time smaller than that related to a single load cycle. Thus, considering the applied load frequency, no significant differences were observed with respect to the static case. All of this will be confirmed by future experimental activities in which the frequency-damping dependency will also be investigated (also beyond the applied frequency). This parameter, assumed constant in this work, could generate a slowdown in the propagation of the elastic wave and, thus, anticipate resonance effects.

Author Contributions: All authors equally contribute to this work. All authors have read and agreed to the published version of the manuscript.

Funding: This research received no external funding.

Conflicts of Interest: The authors declare no conflict of interest.

\section{References}

1. Box, F.; Kodio, O.; O'Kiely, D.; Cantelli, V.; Goriely, A.; Vella, D. Dynamic Buckling of an Elastic Ring in a Soap Film. Phys. Rev. Lett. 2020, 124, 198003. [CrossRef]

2. Kodio, O.; Goriely, A.; Vella, D. Dynamic buckling of an inextensible elastic ring: Linear and nonlinear analyses. Phys. Rev. E 2020, 101, 053002. [CrossRef]

3. Ali, A.Y.; Hasan, H.M. Nonlinear dynamic stability of an imperfect shear deformable orthotropic functionally graded material toroidal shell segments under the longitudinal constant velocity. Proc. Inst. Mech. Eng. Part C J. Mech. Eng. Sci. 2019, 233, 6827-6850. [CrossRef]

4. Amabili, M.; Païdoussis, M.P. Review of studies on geometrically nonlinear vibrations and dynamics of circular cylindrical shells and panels, with and without fluid-structure interaction. Appl. Mech. Rev. 2003, 56, 349-381. [CrossRef]

5. Alijani, F.; Amabili, M. Non-linear vibrations of shells: A literature review from 2003 to 2013. Int. J. Non-Linear Mech. 2014, 58, 233-257. [CrossRef]

6. Kubiak, T. Static and dynamic buckling of thin-walled plate structures. In Static and Dynamic Buckling of Thin-Walled Plate Structures; Springer: London, UK, 2013.

7. Bhimaraddi, A.; Chandrashekhara, K. Nonlinear vibrations of heated antisymmetric angle-ply laminated plates. Int. J. Solids Struct. 1993, 30, 1255-1268. [CrossRef]

8. Kumar, P.; Srinivas, J. Vibration, buckling and bending behavior of functionally graded multi-walled carbon nanotube reinforced polymer composite plates using the layer-wise formulation. Compos. Struct. 2017, 177, 158-170. [CrossRef]

9. Kumar, L.R.; Datta, P.K.; Prabhakara, D.L. Vibration and stability behavior of laminated composite curved panels with cutout under partial in-plane loads. Int. J. Struct. Stab. Dyn. 2005, 5, 75-94. [CrossRef]

10. Kolahchi, R.; Zhu, S.-P.; Keshtegar, B.; Trung, N.-T. Dynamic buckling optimization of laminated aircraft conical shells with hybrid nanocomposite martial. Aerosp. Sci. Technol. 2020, 98, 105656. [CrossRef] 
11. Bigoni, D. Nonlinear Solid Mechanics: Bifurcation Theory and Material Instability; Cambridge University Press: New York, NY, USA, 2012.

12. Javani, M.; Kiani, Y.; Eslami, M.H. Dynamic snap-through of shallow spherical shells subjected to thermal shock. Int. J. Press. Vessel. Pip. 2020, 179, 104028. [CrossRef]

13. Shokravi, M.; Jalili, N. Thermal dynamic buckling of temperature-dependent sandwich nanocomposite quadrilateral microplates using visco-higher order nonlocal strain gradient theory. J. Therm. Stress. 2019, 42, 506-525. [CrossRef]

14. Zhang, J.; Chen, S.; Zheng, W. Dynamic buckling analysis of functionally graded material cylindrical shells under thermal shock. Contin. Mech. Thermodyn. 2019, 32, 1095-1108. [CrossRef]

15. Yasunaga, J.; Uematsu, Y. Dynamic buckling of cylindrical storage tanks under fluctuating wind loading. Thin-Walled Struct. 2020, 150, 106677. [CrossRef]

16. Kubiak, T. Estimation of dynamic buckling for composite columns with open cross-section. Comput. Struct. 2011, 89, 2001-2009. [CrossRef]

17. Zizicas, G.A. Dynamic buckling of thin elastic plates. Trans. ASME 1952, 74, 1257.

18. Budiansky, B.; Roth, R.S. Axisymmetric dynamic buckling of clamped shallow spherical shells. NASA TN 1962, 1510, 597-606.

19. Lindberg, H.E.; Florence, A.L. Dynamic Pulse Buckling; Springer: Dordrecht, The Netherlands, 1987.

20. Labans, E.; Abramovich, H.; Bisagni, C. An experimental vibration-buckling investigation on classical and variable angle tow composite shells under axial compression. J. Sound Vib. 2019, 449, 315-329. [CrossRef]

21. Zaczynska, M.; Abramovich, H.; Bisagni, C. Parametric studies on the dynamic buckling phenomenon of a composite cylindrical shell under impulsive axial compression. J. Sound Vib. 2020, 482, 11546. [CrossRef]

22. Mondal, S.; Ramachandra, L. Nonlinear dynamic pulse buckling of imperfect laminated composite plate with delamination. Int. J. Solids Struct. 2020, 198, 170-182. [CrossRef]

23. Karthick, S.; Datta, P.K. Dynamic instability characteristics of thin plate like beam with internal damage subjected to follower load. Int. J. Struct. Stab. Dyn. 2015, 15, 1450048. [CrossRef]

24. Wang, Y.-H.; Han, Z.-J. Buckling study of composite plates subjected to impact loading. IOP Conf. Ser. Earth Environ. Sci. 2019, 267, 022022.

25. Wang, P.; Li, S.-Q.; Yu, G.-J.; Wu, G.-Y. Dynamic Crushing Behavior of Graded Hollow Cylindrical Shell under Axial Impact Loading. Chin. J. High Press. Phys. 2017, 31, 778-784.

26. Gui, Y.; Ma, J. Buckling of step cylindrical shells under axial impact load. J. Vib. Shock 2019, 38, 200-205, 228.

27. Gui, Y.; Xu, J.; Ma, J. Dynamic Buckling of a Cylindrical Shell with a General Boundary Condition under an Axial Impact. J. Appl. Mech. Tech. Phys. 2019, 60, 712-723. [CrossRef]

28. Zhang, Z.; Taheri, F. Numerical studies on dynamic pulse buckling of FRP composite laminated beams subject to an axial impact. Compos. Struct. 2002, 56, 269-277. [CrossRef]

29. Bažant, Z.P.; Cedolin, L. Stability of Structures; Dover Publication, Inc.: Mineola, NY, USA, 2010.

30. Riccio, A.; Raimondo, A.; Di Caprio, F.; Fusco, M.; Sanitá, P. Experimental and numerical investigation on the crashworthiness of a composite fuselage sub-floor support system. Compos. Part B Eng. 2018, 150, 93-103. [CrossRef]

31. Di Caprio, F.; Ignarra, M.; Marulo, F.; Guida, M.; Lamboglia, A.; Gambino, B. Design of composite stanchions for the cargo subfloor structure of a civil aircraft. Procedia Eng. 2016, 167, 88-96. [CrossRef]

32. Guida, M.; Marulo, F.; Abrate, S. Advances in crash dynamics for aircraft safety. Prog. Aerosp. Sci. 2018, 98, 106-123. [CrossRef]

33. Marulo, F.; Guida, M.; Di Caprio, F.; Ignarra, M.; Lamboglia, A.; Gambino, B. Fuselage Crashworthiness Lower Lobe Dynamic Test. Procedia Eng. 2016, 167, 120-128. [CrossRef]

34. Smith, M. ABAQUS/Standard User's Manual, Version 2019; Dassault Systèmes Simulia Corp: Providence, RI, USA, 2019.

35. Riccio, A.; Saputo, S.; Sellitto, A.; Raimondo, A.; Ricchiuto, R. Numerical investigation of a stiffened panel subjected to low velocity impacts. Key Eng. Mater. 2015, 665, 277-280. [CrossRef] 
36. Riccio, A.; Cristiano, R.; Saputo, S.; Sellitto, A. Numerical methodologies for simulating bird-strike on composite wings. Compos. Struct. 2018, 202, 590-602. [CrossRef]

37. Zucco, G.; Weaver, P.M. The role of symmetry in the post-buckling behaviour of structures. Proc. R Soc. A Math. Phys. Eng. Sci. 2020, 476, 20190609. [CrossRef] [PubMed]

(C) 2020 by the authors. Licensee MDPI, Basel, Switzerland. This article is an open access article distributed under the terms and conditions of the Creative Commons Attribution (CC BY) license (http://creativecommons.org/licenses/by/4.0/). 